\title{
Vascular endothelial growth factor induces anti-Müllerian hormone receptor 2 overexpression in ovarian granulosa cells of in vitro fertilization/intracytoplasmic sperm injection patients
}

\author{
YANQIU FANG $^{1 *}$, XIAODAN LU ${ }^{1,2^{*}}$, LEI LIU ${ }^{1}$, XIUYING LIN ${ }^{1}$, \\ MUNAN SUN ${ }^{1}$, JIANHUA FU ${ }^{1}$, SHUFEN XU ${ }^{1}$ and YAN TAN ${ }^{1,2}$ \\ ${ }^{1}$ Reproductive Medical Center, Jilin Province People's Hospital, Changchun, Jilin 130021; \\ ${ }^{2}$ Department of Immunology, The First Affiliated Hospital of Jilin University, Changchun, Jilin 130012, P.R. China
}

Received May 5, 2015; Accepted March 8, 2016

DOI: $10.3892 / \mathrm{mmr} .2016 .5173$

\begin{abstract}
Misregulation of vascular endothelial growth factor A (VEGF-A) has been implicated in numerous types of ovarian disease, such as polycystic ovarian syndrome, ovarian hyperstimulation syndrome, endometriosis and ovarian cancer. VEGF regulates blood vessel permeability and angiogenesis. In our previous study, VEGF-regulated gene expression was profiled in the uterus of a transgenic mouse model with repressed VEGF expression, which indicated that VEGF is an important regulator in controlling gene expression in the uterus. The anti-Müllerian hormone (AMH) is expressed by ovarian granulosa cells (GCs) and acts through its type 2 receptor, AMH receptor 2 (AMHR2). Serum AMH levels are used to predict ovarian reserves and the small antral follicles contribute markedly to the serum AMH level. $\mathrm{AMH}$ recruits primordial follicles and inhibits excessive follicular development by follicular stimulating hormone (FSH). However, AMH may be influenced by suppression of gonadotrophin secretion and VEGF inhibition. In the current study, human primary ovarian GCs were isolated from ovarian follicle fluid of in vitro fertilization/intracytoplasmic sperm injection cycles (IVF/ICSI). It was identified that the FSH receptor was consistently expressed in the isolated cells. VEGF-A treatment stimulated AMHR2 overexpression at the gene and protein levels. In addition, VEGF induced AMHR2 expression on the surface of the isolated GCs from mature follicles. The VEGF treatment was also performed in an ovarian granulosa-like cell line, KGN. AMH and AMHR2
\end{abstract}

Correspondence to: Dr Yan Tan, Reproductive Medical Center, Jilin Province People's Hospital, 1183 Gongnong Road, Changchun, Jilin 130021, P.R. China

E-mail: tanyan49@hotmail.com

${ }^{*}$ Contributed equally

Key words: vascular endothelial growth factor, ovarian granulosa cells, anti-Müllerian hormone receptor 2 are co-expressed in normal GCs; however, as a result of VEGF misregulation, AMHR2 overexpression increases AMH binding, which may attenuate follicular or oocyte maturation. However, the associated function and underlying mechanism requires further investigation.

\section{Introduction}

The anti-Müllerian hormone (AMH) is produced in the ovarian granulosa cells (GCs). Through the specific receptor, AMH receptor 2 (AMHR2), AMH limits the formation of primary follicles and inhibits excessive follicular recruitment by follicle stimulating hormone (FSH) $(1,2)$. The expression levels of AMH have been used as the indexes to predict ovarian reserves and ovarian response in assisted reproductive technology $(3,4)$. In human ovaries, early stage antral follicles contribute markedly to the serum AMH concentration (5). AMHR2 is a single transmembrane serine/threonine kinase receptor of the transforming growth factor $\beta$ (TGF $\beta$ ) receptor family, which is expressed on ovarian GCs (6). The presence of AMHR2 is also observed in ovarian cancer cell lines that respond positively to treatment with recombinant AMH (7). Thus, the receptor and ligand may be important diagnostic factors or therapeutic tools.

The human ovary is a highly vascularized organ. As a key regulator of vascularization, vascular endothelial growth factor (VEGF) is crucial in regulating follicular growth, corpus luteum development and maintaining ovarian functions (8). VEGF is expressed in the ovarian granulosa, theca and granulosa lutein cells (9) and acts by binding to the tyrosine kinase receptors, VEGFR1 and 2 in the ovary. Marked production and secretion of follicular VEGF occur in response to gonadotrophin stimulation (10). Furthermore, hypersecretion of VEGF is frequently observed in patients with polycystic ovarian syndrome (PCOS) $(11,12)$. It has been proposed that VEGF, by regulating vascular permeability, induces blood vessel leaking in ovaries exhibiting ovarian hyperstimulation syndrome (OHSS) (13). Notably, in a transgenic mouse model with engineered inducible repression of VEGF, mice were observed to become infertile upon VEGF repression (14). By digital gene expression assays, 831 uterus-specific and 
2,398 VEGF-regulated differentially expressed genes were identified in the mouse uterus, which indicated that VEGF exerts a regulatory role in gene expression in the uterus.

The majority of studies regarding AMH focus on the early stage of follicle development. In a study on marmosets, AMH levels were decreased in early preantral follicles as a result of the suppression of gonadotrophin secretion and VEGF inhibition (15). The regulatory role of VEGF with regard to $A M H$ and $A M H R 2$ signaling has remained to be elucidated in mature follicles. In the present study, VEGF, VEGFR2, FSH receptor (FSHR), AMH, AMHR2 and TGF $\beta$ expression changes were analyzed following FSH and/or VEGF treatment in human primary GCs, which were isolated from IVF/ICSI patients. Furthermore, the elevation of AMHR2 expression levels by VEGF in the ovarian granulosa-like KGN cells was identified.

\section{Materials and methods}

The current study was performed on cultured GCs, which were derived from human ovarian follicular fluid. The female participants provided written informed consent, and the protocol of the study was approved by the ethical committee of Jilin Province People's Hospital (Changchun, China).

Primary ovarian GCs. GCs were isolated at the time of oocyte pick-up from $18 \mathrm{IVF} / \mathrm{ICSI}$ patients with male factors only

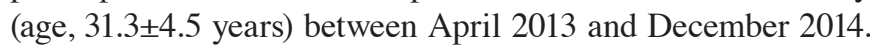
Eighteen follicular fluid samples were collected and the follicular aspirates obtained from individual patients were centrifuged at $900 \mathrm{x} g$ at room temperature. Blood contaminants were removed from GCs by Histopaque ${ }^{\circledR} 1077$ (Sigma-Aldrich, St. Louis, MO, USA) gradient centrifugation at $800 \mathrm{x} \mathrm{g}$ for $20 \mathrm{~min}$ at room temperature. The GC pellet was resuspended in a $20-\mathrm{ml}$ volume of medium [Dulbecco's modified Eagle's medium/Ham's Nutrient Mixture F-12 (Gibco, Thermo Fisher Scientific, Inc., Waltham, MA, USA) with $10 \%$ fetal bovine serum (Beyotime Institute of Biotechnology, Inc., Haimen, China)] and washed by a further 10 -min centrifugation at $500 \mathrm{x}$ g. The GC pellet was resuspended in $1 \mathrm{ml}$ GC preparation medium containing $0.02 \%(\mathrm{w} / \mathrm{v})$ EDTA and gentle repeated pipetting was performed to break up any cellular clumps. Following further washing, the cell stock was resuspended in the GC culture medium. The cells were seeded in six-well cell culture plates at a density of 100,000 cells/well in medium. Following an overnight incubation $\left(37^{\circ} \mathrm{C}, 5 \% \mathrm{CO}_{2}\right)$, cells were treated with $30 \mathrm{ng} / \mathrm{ml}$ human recombinant FSH (450 IU; GONAL-F; Merck Biopharma China, Beijing, China) and/or 100 ng/ml VEGF-A (CB055-0231; ExCell Biotech, Shanghai, China) for 24 or $48 \mathrm{~h}$. Phosphate-buffered saline (PBS) was added to the control group as a vehicle.

Cell line. The human granulosa tumor-derived cell line, KGN was obtained from Riken BioResource Center (Riken Cell Bank, Tsukuba, Japan). The KGN cells used in these experiments were passages 8-12. The cell line was validated by short tandem repeat polymorphism analysis, which was performed by Riken Biosource Center.

Gene expression analysis. Total RNA was isolated from primarily cultured cells according to previous methods (16).

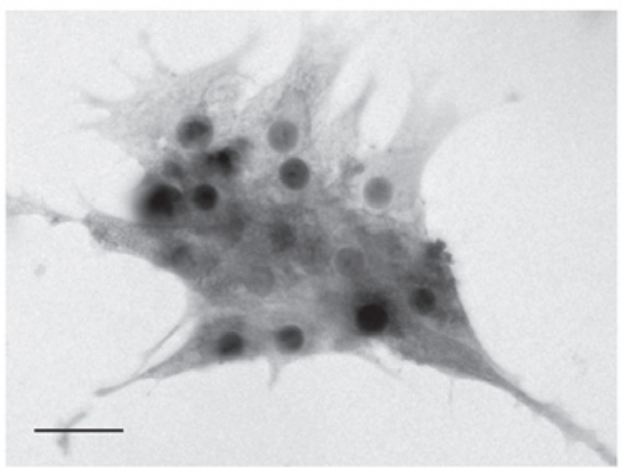

Figure 1. FSHR was expressed on isolated human luteinized granulosa cells Representative immunocytochemistry of FSHR $(\mathrm{n}=3)$. Scale bar, $20 \mu \mathrm{m}$. FSHR, follicle-stimulating hormone receptor.

First-strand cDNA synthesis was performed using $1 \mu \mathrm{g}$ total RNA in a $20-\mu 1$ volume. Random primers and 200 units Moloney murine leukemia virus reverse transcriptase (Takara Biotechnology Co., Ltd., Dalian, China) were used for reverse transcription (RT). The SYBR Green PCR master mix (Roche Diagnostics, Shanghai, China) was used as a double-stranded DNA-specific fluorescent dye. Gene expression was assessed by RT-quantitative polymerase chain reaction (qPCR) using the Applied Biosystems 7500 Real-Time PCR system (Thermo Fisher Scientific, Inc.). PCR conditions were as follows: 2 min at $50^{\circ} \mathrm{C}$ and $10 \mathrm{~min}$ at $95^{\circ} \mathrm{C}$, followed by 40 cycles of $95^{\circ} \mathrm{C}$ for $30 \mathrm{sec}, 60^{\circ} \mathrm{C}$ for $30 \mathrm{sec}$, and $72^{\circ} \mathrm{C}$ for $30 \mathrm{sec}$. The specificity of amplification was confirmed by melting curve analysis and gel electrophoresis. All results were normalized to the levels of $18 \mathrm{~S}$ ribosomal (r)RNA, and relative quantification was calculated using relative quantification $(\Delta \Delta \mathrm{Cq})$ values for each biological replicate $(16,17)$. Values are expressed as the mean \pm standard error of the mean (SEM; triplicate samples and three repeats). The following primer sequences (Genewiz, Suzhou, China) were used for RT-PCR: Forward, CGAAGTGGTGAAGTT CATGG and reverse, GTACTCGATCTCATCAGGGT for VEGF; forward, CACTGGCTTCTACAGCTGCA and reverse, CGAAAGGTCTACCTGTATC for VEGFR1; forward, CGG TCAACAAAGTCGGGAGA and reverse, CAGTGCACCACA AAGACACG for VEGFR2; forward, GGAACATCATAG TGCTAGTG and reverse, CCAGTCAATGGCATAGTTGT for FSHR; forward, GTCCTACACCTGGAGGAAGT and reverse, AGCCCTCGTCACAGTGACCT for AMH; forward, GATTTGAGGCCTGACAGCAG and reverse, GCCAGGTGG ATGGGATGTAG for AMHR2; forward, ACTACTACGCCA AGGAGGTC and reverse, CGGAGCTCTGATGTGTTGAA for TGF $\beta$; and forward, CATTCGAACGTCTGCCCTAT and reverse, GATGTGGTAGCCGTTTCTCA for 18S rRNA.

Immunocytochemistry. Cells were fixed in $4 \%$ paraformaldehyde (Sigma-Aldrich) for $30 \mathrm{~min}$. Cells were blocked with 5\% bovine serum albumin (Sigma-Aldrich) in PBS for $1 \mathrm{~h}$ at room temperature and incubated overnight with rabbit anti-human FSHR antibody (cat. no. BA2317; Beijing Bioss Biosynthesis Biotechnology Co., Ltd., Beijing, China) or rabbit anti-human MIS antibody (cat. no. sc-6886; Santa Cruz Biotechnology, Inc., Dallas, TX, USA) primary antibodies (dilution, 1:500) at $4^{\circ} \mathrm{C}$ and horseradish peroxidase (HRP)-conjugated goat 
A

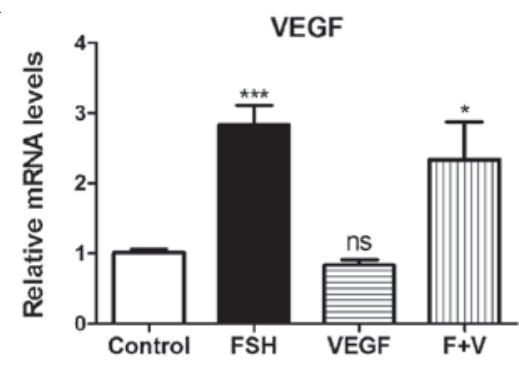

C

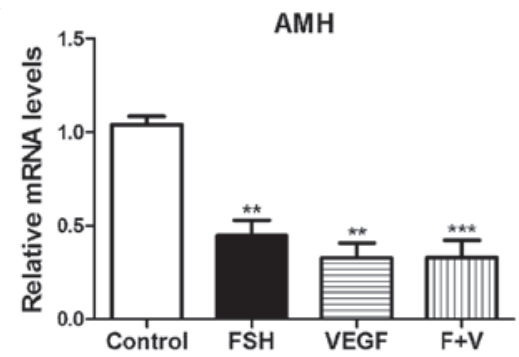

$\mathbf{E}$

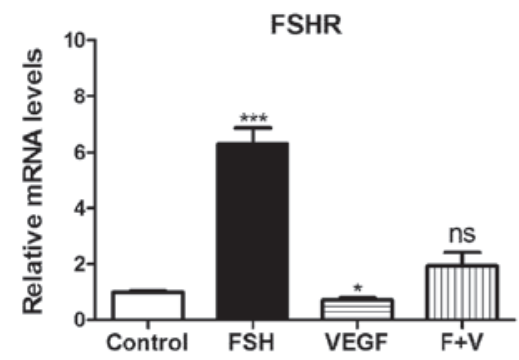

B

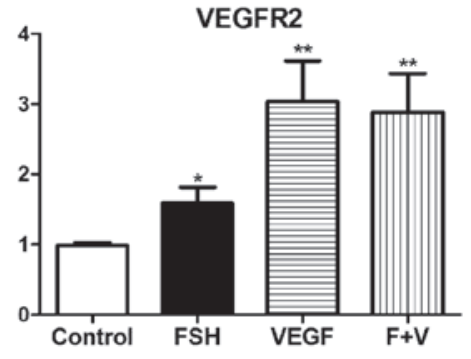

D

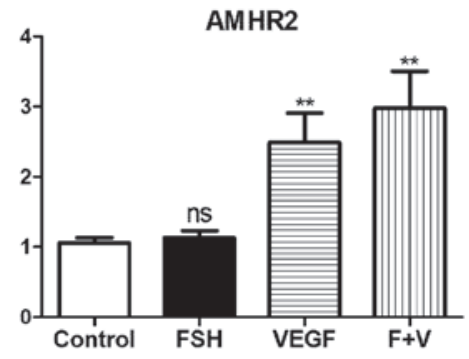

$\mathbf{F}$

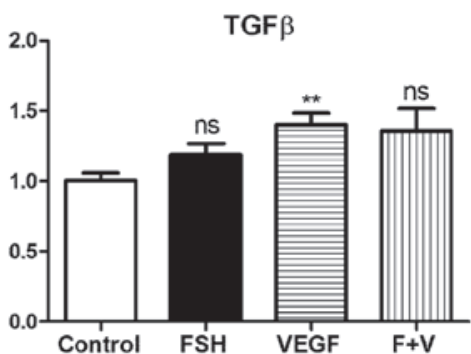

Figure 2. VEGF treatment induced changes at the mRNA level of primary granulosa cells. $\mathrm{rhFSH}(30 \mathrm{ng} / \mathrm{ml}), \mathrm{rhVEGF}(100 \mathrm{ng} / \mathrm{ml}), \mathrm{and} \mathrm{rhFSH}(30 \mathrm{ng} / \mathrm{ml})$ and rhVEGF (100 ng/ml; F + V) were used to treat the primary granulosa cells. Gene expression levels of (A) $V E G F$, (B) $V E G F R 2$, (C) $A M H$, (D) $A M H R 2$, (E) FSHR and (F) TGF $\beta$ were analyzed by reverse transcription quantitative polymerase chain reaction (n=6). Data are presented as means \pm standard error of the mean. ${ }^{*} \mathrm{P}<0.05,{ }^{* *} \mathrm{P}<0.01,{ }^{* * *} \mathrm{P}<0.001$ compared with the vehicle control. ns, no significance; VEGF, vascular endothelial growth factor; rh, recombinant human; AMH, anti-Müllerian hormone; FSHR, follicle-stimulating hormone receptor; TGF $\beta$, transforming growth factor $\beta$.

anti-rabbit immunoglobulin $\mathrm{G}(\mathrm{IgG})$ secondary antibody (cat. no. SA1028; Beijing Bioss Biosynthesis Biotechnology Co., Ltd.) (dilution, 1:1,000) for $2 \mathrm{~h}$ at room temperature, followed by 3,3'-diaminobenzidine and hematoxylin staining (Beijing Chemical Co., Beijing, China). Washes with PBS (three times for 3 min each) were performed between incubations. A microscope (CX31; Olympus Corp., Tokyo, Japan) and Image $\mathbf{J}$ software (version 1.46r; National Institutes of Health, Bethesda, MD, USA) were used to perform analyses.

Protein analysis. For western blot analysis, cells were lysed in radioimmunoprecipitation assay buffer $[0.5 \%$ Nonidet $\mathrm{P}-40$, $0.1 \%$ sodium deoxycholate, $150 \mathrm{mM} \mathrm{NaCl}, 50 \mathrm{mM}$ Tris-Cl ( $\mathrm{pH}$ 7.5); Beijing Chemical Co.]. The lysates were resolved by 10\% SDS-PAGE (Pierce Biotechnology, Inc., Rockford, IL, USA), transferred to a polyvinylidene difluoride membrane (EMD Millipore, Billerica, MA, USA) at $10 \mathrm{~V}$ over $2 \mathrm{~h}$ and probed with rabbit anti-human FSHR, rabbit anti-human MIS and mouse anti-human GAPDH antibody (cat. no. sc-20357; Santa Cruz Biotechnology, Inc.) at 1:500 dilution at $4^{\circ} \mathrm{C}$ overnight. The secondary antibody conjugated to HRP (goat anti-rabbit IgG-HRP; cat. no. sc-2030 or goat anti-mouse
IgG-HRP; cat. no. sc-2031; Santa Cruz Biotechnology, Inc.) was applied successively at 1:1,000 dilution followed by incubation at room temperature for $2 \mathrm{~h}$. Blots were developed using the Chemiluminescence WB solution ABC kit (DW101-01; Beijing TransGen Biotech, Beijing, China).

Statistical analysis. Values are expressed as the mean \pm SEM. Statistical analysis was performed using an unpaired $t$-test with GraphPad Prism software (version 5.1; GraphPad Inc., La Jolla, CA, USA). Grouped data were analyzed by one-way analysis of variance and $\mathrm{P}<0.05$ was considered to indicate a statistically significant difference.

\section{Results}

AMHR2 expression in primary GCs. Human luteinized GCs were isolated from the follicle fluid of IVF/ICSI patients. FSHR expression is considered to be the biological marker of ovarian GCs, thus, the isolated cells were identified by immunocytochemistry staining of FSHR (Fig. 1). The negative controls were established by incubation with an equal quantity of non-immunized rabbit IgG. 
A

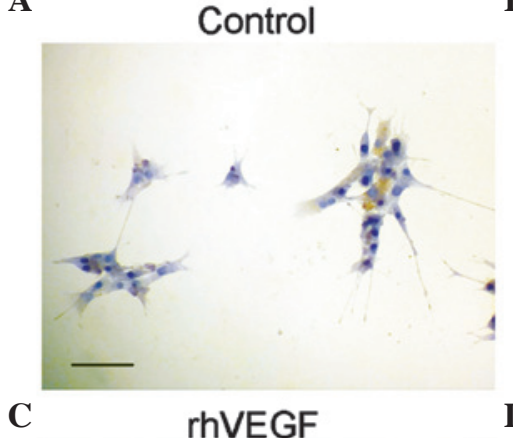

C

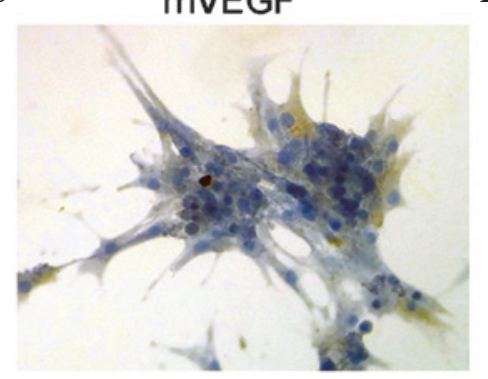

B rhFSH

D rhFSH+rhVEGF

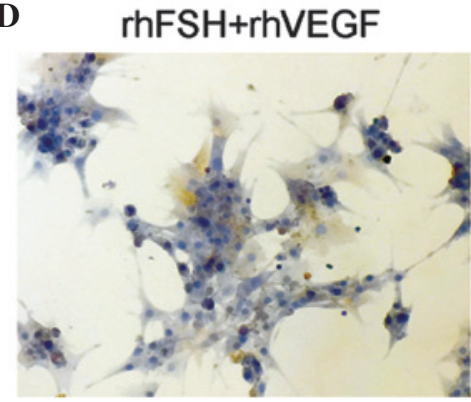

Figure 3. AMHR2 expression in primary human luteinized granulosa cells. (A) Control (treated with vehicle). Primary cells were treated with (B) rhFSH (30 ng/ml); (C) rhVEGF (100 ng/ml); and (D) rhFSH (30 ng/ml) and rhVEGF (100 ng/ml; rhFSH +rhVEGF). Representative immunocytochemistry with anti-AMHR2 was conducted (n=3). Scale bar, $40 \mu \mathrm{m}$. rh, recombinant human; FSH, follicle-stimulating hormone; VEGF, vascular endothelial growth factor; AMHR2, anti-Müllerian hormone receptor 2.

A

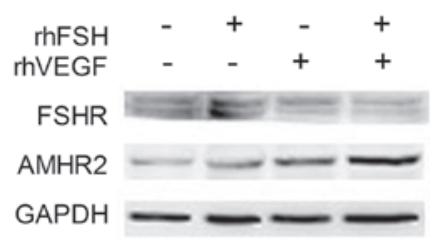

B

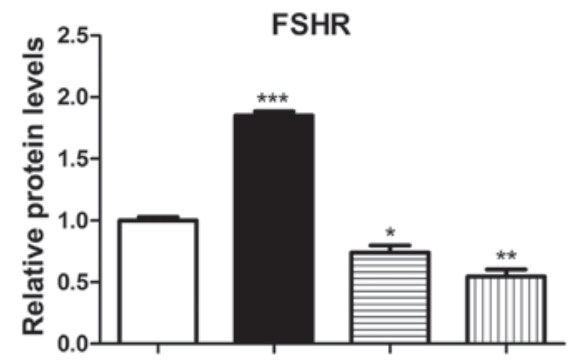

C

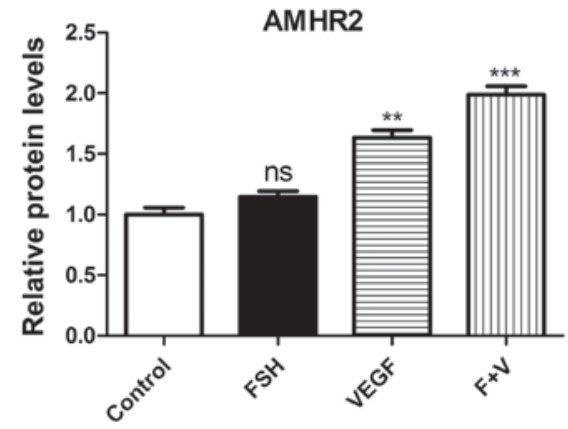

Figure 4. VEGF treatment induces changes in mRNA expression levels in primary granulosa cells. Primary cells were treated with $\mathrm{rhFSH}(30 \mathrm{ng} / \mathrm{ml})$, rhVEGF $(100 \mathrm{ng} / \mathrm{ml})$, and $\mathrm{rhFSH}(30 \mathrm{ng} / \mathrm{ml})$ and VEGF $(100 \mathrm{ng} / \mathrm{ml} ; \mathrm{F}+\mathrm{V})$. (A) Representative western blot analysis and the quantification of (B) FSHR and (C) AMHR2 expression levels $(n=3)$. Values are expressed as the mean \pm standard error of the mean. ${ }^{*} \mathrm{P}<0.05,{ }^{* *} \mathrm{P}<0.01,{ }^{* * * *} \mathrm{P}<0.001$ vs. control. rh, recombinant human; FSH, follicle-stimulating hormone; VEGF, vascular endothelial growth factor; AMHR2, anti-Müllerian hormone receptor 2, ns, no significance.
A

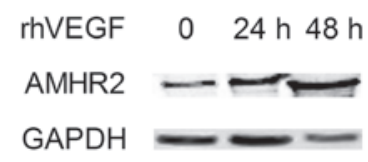

B

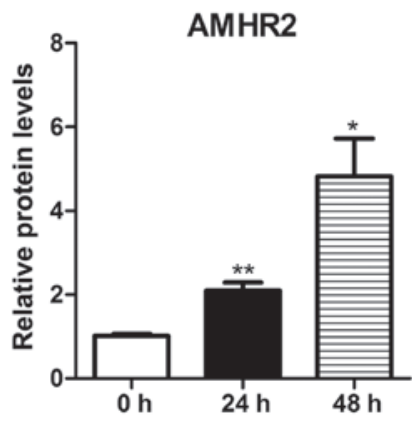

Figure 5. VEGF induced representative AMHR2 protein expression in the KGN cells. KGN cells were treated with rhVEGF $(100 \mathrm{ng} / \mathrm{ml})$ for 0,24 and $48 \mathrm{~h}$. (A) Representative western blot analysis and (B) quantification of AMHR2 protein expression $(n=3)$. Data are presented as means \pm standard error of the mean. ${ }^{*} \mathrm{P}<0.05,{ }^{* *} \mathrm{P}<0.01$ vs. $0 \mathrm{~h}$. rh, recombinant human; AMHR2, anti-Müllerian hormone receptor 2; VEGF, vascular endothelial growth factor.

FSH- and VEGF-induced gene expression varies in primary GCs. Gonadotrophin contributes to GC growth and proliferation (15). To investigate the gonadotrophin- and VEGF-induced gene expression changes, RT-qPCR was performed on the primary GCs, and human recombinant FSH and VEGF were used to treat the cells. The mRNA expression of VEGF was significantly elevated as a result of treatment with FSH, and FSH + VEGF by 2.8- $(\mathrm{P}<0.05)$ and 2.3-fold $(\mathrm{P}<0.01)$, respectively; however, no significant difference was noted in the VEGF only group (Fig. 2A). VEGFR2 mRNA expression levels 
were significantly increased in the VEGF and VEGF plus FSH groups by $\sim 3$-fold $(\mathrm{P}<0.01)$ and in the FSH group by $\sim 1.5$-fold $(\mathrm{P}<0.05)$ (Fig. 2B), whereas $A M H$ mRNA expression levels were significantly decreased in all groups $(\mathrm{P}<0.01)$ (Fig. $2 \mathrm{C})$. Compared with the control, the AMHR 2 mRNA expression levels increased as a result of VEGF, and FSH + VEGF treatment by 2.4- and 3.2-fold, respectively $(\mathrm{P}<0.01)$; however, the increase observed in the FSH only treatment group was not significant (Fig. 2D). FSHR mRNA expression levels increased due to FSH treatment, by 6.2 -fold $(\mathrm{P}<0.001)$ and significantly decreased following VEGF treatment, by 0.7 -fold $(\mathrm{P}<0.05)$ (Fig. 2E). TGF $\beta$ mRNA expression levels increased significantly as a result of VEGF treatment $(\mathrm{P}<0.01$; Fig. $2 \mathrm{~F})$.

FSH- and VEGF-induced protein expression varies in primary GCs. AMHR2 expression was observed in the primary ovarian GCs by immunocytochemical staining (Fig. 3). Expression of the FSHR and AMHR2 protein was analyzed by western blotting. FSHR protein expression was significantly increased by FSH stimulation $(\mathrm{P}<0.001)$, and significantly decreased by VEGF and VEGF + FSH treatment (Fig. 4A and B). Conversely, AMHR2 protein expression was significantly increased as a result of VEGF and VEGF + FSH treatment $(\mathrm{P}<0.01)$. Although the AMHR2 expression was increased as a result of FSH treatment, the difference was not significant (Fig. 4C).

VEGF stimulated AMHR2 overexpression in KGN cells. The human granulosa-like cell line, $\mathrm{KGN}$ is an ovarian cancer cell line that expresses FSHR (18). The KGN GC tumor cells were derived from a patient who presented with a recurrent, metastasized granulosa cell tumor in the pelvic region. The cell line maintains ovarian GC features, such as expression of the FSH receptor and production of estrogen in response to FSH (7). In the present study, the expression levels on primary cells were varied in specific individuals. To demonstrate the induction of AMHR2, KGN cells were treated with VEGF. The cells were treated with $100 \mathrm{ng} / \mathrm{ml}$ VEGF for 24 and $48 \mathrm{~h}$, and the representative AMHR 2 protein levels increased by 2- and 5-fold, respectively (Fig. 5A and B).

\section{Discussion}

VEGF is important in maintaining and regulating the functions of the female reproductive system. White adipose tissue, which is the major organ of VEGF secretion, surrounds the human ovaries and uterus and assists with maintaining their functions. VEGF has been detected in the follicular fluid of PCOS females undergoing controlled ovarian hyperstimulation, which modulates the effects of gonadotrophins in GCs $(8,10)$. AMH is exclusively produced by ovarian GCs of the developing preantral and antral follicles $(19,20)$. Ovarian function and reserve can be assessed by serum AMH levels to evaluate infertility. Age-specific serum AMH levels and the antral follicle count (AFC) baseline are evaluated to predict ovarian reserve, particularly in females with PCOS (21-23).

$\mathrm{AMH}$ acts via its type II receptor, AMHR2, which has recently been increasingly investigated. In a previous study, AMHR2 expression was evaluated in the mouse uterus (13). Genetic variants of $A M H R 2$ appear to be associated with unexplained infertility and PCOS risk (24). A primary study demonstrated that antral follicles (size, 5-8 $\mathrm{mm}$ ) contribute markedly to serum AMH levels, and the AMHR2 gene is co-expressed with $A M H$ in the GCs of small antral follicles; however, the correlation between $A M H R 2$ gene expression level and follicle fluid AMH concentration was not identified to be significant (5). In the present study, FSHR and AMHR2 were detectable in the ovarian follicular fluid-derived GCs of the patients. $A M H$ mRNA levels were decreased in response to FSH and/or VEGF treatment. Furthermore, TGF $\beta$ is important in controlling cell proliferation and exerts a regulatory role in ovarian angiogenesis (25). TGF $\beta$ expression levels were increased in response to VEGF treatment in the current study. Thus, VEGF may have prompted the maturation of GCs and the reduction in $\mathrm{AMH}$ expression.

In the present study, AMHR2 expression levels were increased when the AMH expression level was repressed following VEGF exposure. The in vitro study of KGN cells indicated that the induction of AMHR2 by VEGF was time-dependent. VEGF and its receptor, VEGFR2 are highly expressed in ovarian GC tumors. In the present study, AMHR2 protein expression was increased in response to VEGF stimulation in the KGN cells. In a previous study, high levels of circulating VEGF were observed in the serum of patients with primary GC tumors (26). Thus, elevated VEGF levels increase AMHR2 levels in carcinoma tissues, which may contribute to the malignancy of the tumor.

In conclusion, AMH exerts paracrine and hormonal actions, and expression levels of the specific receptor, AMHR2 also varies in different cells or tissues. VEGF misregulation increases AMHR2 expression, which may result in binding of $\mathrm{AMH}$ from the circulation, leading to paracrine $\mathrm{AMH}$ binding and attenuation of the maturation of follicles in individuals using assisted reproductive technology. AMH may exert other actions in reproduction-associated organs; however, this requires further investigation.

\section{Acknowledgements}

The present study was supported by grants from the Jilin Provincial Science and Technology department (grant nos. 20150414023GH and 20150520038JH) and the China Postdoctoral Science Foundation (grant no. 2014M551176).

\section{References}

1. Pellatt L, Rice S, Dilaver N, Heshri A, Galea R, Brincat M, Brown K, Simpson ER and Mason HD: Anti-Mullerian hormone reduces follicle sensitivity to follicle-stimulating hormone in human granulosa cells. Fertil Steril 96: 1246-1251.e1, 2011.

2. Durlinger AL, Gruijters MJ, Kramer P, Karels B, Ingraham HA, Nachtigal MW, Uilenbroek JT, Grootegoed JA and Themmen AP: Anti-Müllerian hormone inhibits initiation of primordial follicle growth in the mouse ovary. Endocrinology 143: 1076-1084, 2002.

3. Gleicher N, Kim A, Kushnir V, Weghofer A, Shohat-Tal A Lazzaroni E, Lee HJ and Barad DH: Clinical relevance of combined FSH and AMH observations in infertile women. J Clin Endocrinol Metab 98: 2136-2145, 2013.

4. Iliodromiti S, Kelsey TW, Wu O, Anderson RA and Nelson SM: The predictive accuracy of anti-Müllerian hormone for live birth after assisted conception: A systematic review and meta-analysis of the literature. Hum Reprod Update 20: $560-570,2014$ 
5. Jeppesen JV, Anderson RA, Kelsey TW, Christiansen SL, Kristensen SG, Jayaprakasan K, Raine-Fenning N, Campbell BK and Yding Andersen C: Which follicles make the most anti-Mullerian hormone in humans? Evidence for an abrupt decline in AMH production at the time of follicle selection. Mol Hum Reprod 19: 519-527, 2013.

6. Imhoff FM, Yang D, Mathew SF, Clarkson AN, Kawagishi Y, Tate WP, Koishi K and McLennan IS: The type 2 anti-Müllerian hormone receptor has splice variants that are dominant-negative inhibitors. FEBS Lett 587: 1749-1753, 2013.

7. Fu D, Lv X, Hua G, He C, Dong J, Lele SM, Li DW, Zhai Q, Davis JS and Wang C: YAP regulates cell proliferation, migration and steroidogenesis in adult granulosa cell tumors. Endocr Relat Cancer 21: 297-310, 2014.

8. Kaya A, Atabekoglu CS, Kahraman K, Taskin S, Ozmen B, Berker B and Sonmezer M: Follicular fluid concentrations of IGF-I, IGF-II, IGFBP-3, VEGF, AMH and inhibin-B in women undergoing controlled ovarian hyperstimulation using $\mathrm{GnRH}$ agonist or GnRH antagonist. Eur J Obstet Gynecol Reprod Biol 164: 167-171, 2012.

9. Abramovich D, Irusta G, Bas D, Cataldi NI, Parborell F and Tesone M: Angiopoietins/TIE2 system and VEGF are involved in ovarian function in a DHEA rat model of polycystic ovary syndrome. Endocrinology 153: 3446-3456, 2012.

10. Doyle LK, Walker CA and Donadeu FX: VEGF modulates the effects of gonadotropins in granulosa cells. Domest Anim Endocrinol 38: 127-137, 2010.

11. Peitsidis P and Agrawal R: Role of vascular endothelial growth factor in women with PCO and PCOS: A systematic review. Reprod Biomed Online 20: 444-452, 2010.

12. Di Pietro M, Parborell F, Irusta G, Pascuali N, Bas D, Bianchi MS, Tesone $\mathrm{M}$ and Abramovich D: Metformin regulates ovarian angiogenesis and follicular development in a female polycystic ovary syndrome rat model. Endocrinology 156: 1453-1463, 2015.

13. Kumar P, Sait SF, Sharma A and Kumar M: Ovarian hyperstimulation syndrome. J Hum Reprod Sci 4: 70-75, 2011.

14. Ji Y, Lu X, Zhong Q, et al: Transcriptional profiling of mouse uterus at pre-implantation stage under VEGF repression. PLoS One 8: e57287, 2013

15. Thomas FH, Telfer EE and Fraser HM: Expression of anti-Mullerian hormone protein during early follicular development in the primate ovary in vivo is influenced by suppression of gonadotropin secretion and inhibition of vascular endothelial growth factor. Endocrinology 148: 2273-2281, 2007.
16. Lu X, Ji Y, Zhang L, Zhang Y, Zhang S, An Y, Liu P and Zheng Y: Resistance to obesity by repression of VEGF gene expression through induction of brown-like adipocyte differentiation. Endocrinology 153: 3123-3132, 2012

17. Livak KJ and Schmittgen TD: Analysis of relative gene expression data using real-time quantitative PCR and the 2(-Delta Delta C(T)) Method. Methods 25: 402-408, 2001.

18. Nishi Y, Yanase T, Mu Y, Oba K, Ichino I, Saito M, Nomura M, Mukasa C, Okabe T, Goto K, et al: Establishment and characterization of a steroidogenic human granulosa-like tumor cell line, KGN, that expresses functional follicle-stimulating hormone receptor. Endocrinology 142: 437-445, 2001.

19. Peluso C, Fonseca FL, Rodart IF, Cavalcanti V, Gastaldo G, Christofolini DM, Barbosa CP and Bianco B: $\mathrm{AMH}$ : An ovarian reserve biomarker in assisted reproduction. Clin Chim Acta 437: 175-182, 2014.

20. Carlsson IB, Scott JE, Visser JA, Ritvos O, Themmen AP and Hovatta O: Anti-Müllerian hormone inhibits initiation of growth of human primordial ovarian follicles in vitro. Hum Reprod 21: 2223-2227, 2006.

21. Cui Y, Shi Y, Cui L, Han T, Gao X and Chen ZJ: Age-specific serum antimüllerian hormone levels in women with and without polycystic ovary syndrome. Fertil Steril 102: 230-236.e2, 2014.

22. Li HW, Lee VC, Lau EY, Yeung WS, Ho PC and Ng EH: Role of baseline antral follicle count and anti-Mullerian hormone in prediction of cumulative live birth in the first in vitro fertilisation cycle: A retrospective cohort analysis. PLoS One 8: e61095, 2013

23. Panchal S and Nagori C: Comparison of anti-mullerian hormone and antral follicle count for assessment of ovarian reserve. J Hum Reprod Sci 5: 274-278, 2013.

24. Rigon C, Andrisani A, Forzan M, D'Antona D, Bruson A, Cosmi E, Ambrosini G, Tiboni GM and Clementi $M$ : Association study of AMH and AMHRII polymorphisms with unexplained infertility. Fertil Steril 94: 1244-1248, 2010.

25. Kuo SW, Ke FC, Chang GD, Lee MT and Hwang JJ: Potential role of follicle-stimulating hormone (FSH) and transforming growth factor (TGF $\beta 1$ ) in the regulation of ovarian angiogenesis. J Cell Physiol 226: 1608-1619, 2011.

26. Färkkilä A, Anttonen M, Pociuviene J, Leminen A, Butzow R, Heikinheimo $\mathrm{M}$ and Unkila-Kallio L: Vascular endothelial growth factor (VEGF) and its receptor VEGFR-2 are highly expressed in ovarian granulosa cell tumors. Eur J Endocrinol 164: 115-122, 2011. 